\title{
Theoretical Study of Formation of Methanol under Hydrothermal Conditions
}

\author{
Satoshi Inaba* \\ School of International Liberal Studies, Waseda University, 1-6-1 Nishiwaseda, \\ Shinjuku-ku, Tokyo 169-8050, Japan \\ E-mail: satoshi.inaba@waseda.jp \\ Phone: 81-3-5286-1730
}




\section{Supporting Information Available}
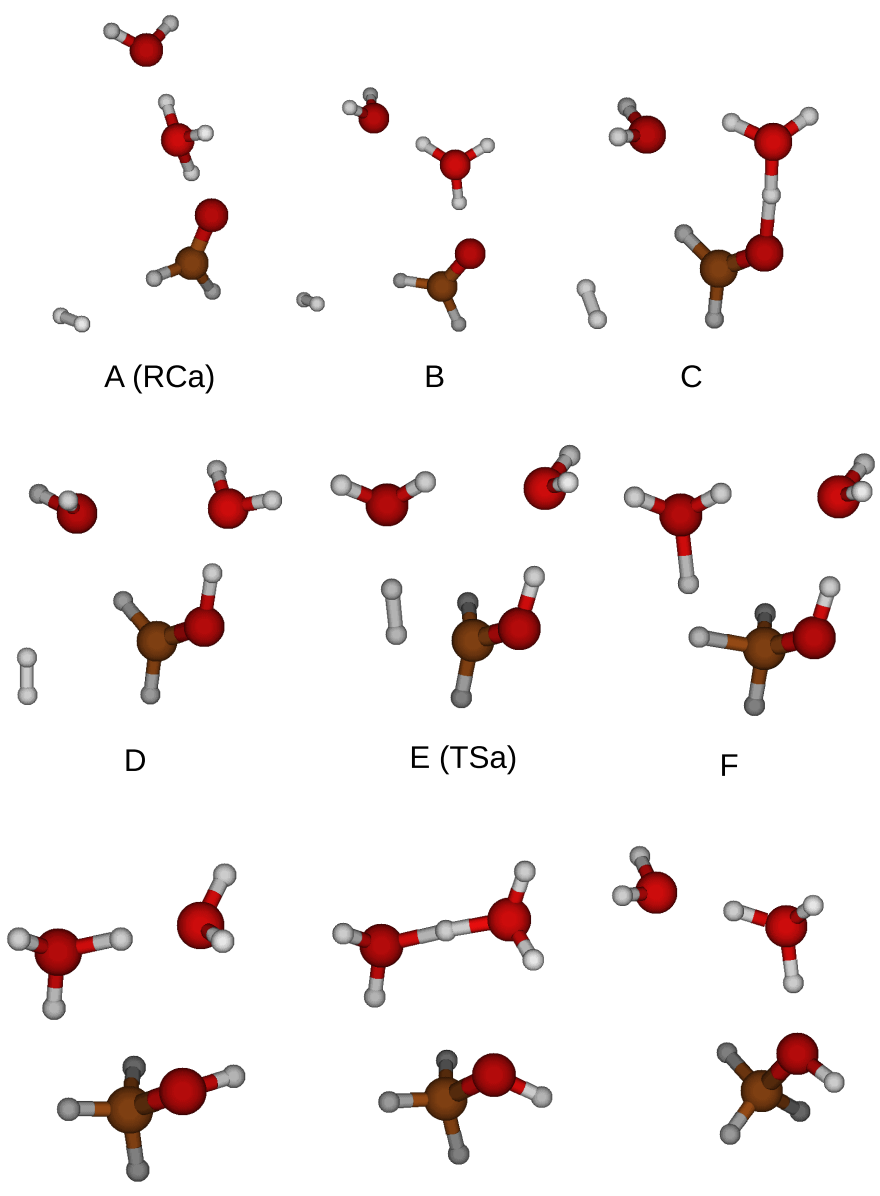

G

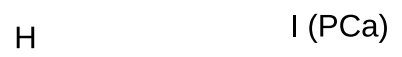

Figure 1: Calculated transformations of molecular structures for the acid catalyzed reduction of a formaldehyde along the IRC. 


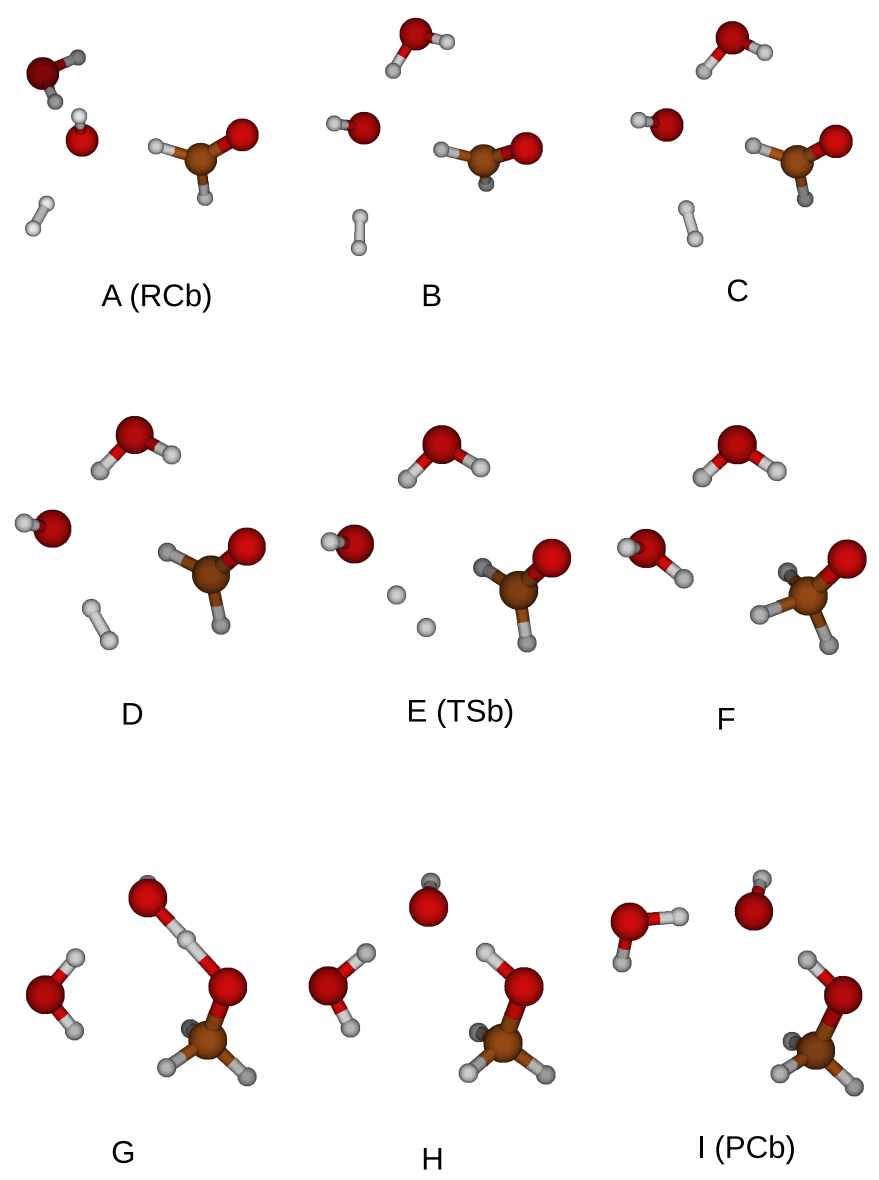

Figure 2: Calculated transformations of molecular structures for the base catalyzed reduction of a formaldehyde along the IRC. 